\title{
Antioxidant Enzymes and Lipid Peroxidation in Alloxan-Induced Diabetic Rabbits
}

\author{
Enefe Ndidi Glory ${ }^{1, *}$, Ebuehi Osaretin Albert ${ }^{2}$ \\ ${ }^{1}$ Department of Veterinary Physiology and Biochemistry, Faculty of Veterinary Medicine, University of Abuja, Abuja, Nigeria \\ ${ }^{2}$ Department of Biochemistry, College of Medicine, University of Lagos, Idiaraba, Lagos State Nigeria
}

Email address:

nd1d1@yahoo.com (E. N. Glory)

${ }^{*}$ Corresponding author

To cite this article:

Enefe Ndidi Glory, Ebuehi Osaretin Albert. Antioxidant Enzymes and Lipid Peroxidation in Alloxan-Induced Diabetic Rabbits. Animal and Veterinary Sciences. Vol. 6, No. 2, 2018, pp. 27-34. doi: 10.11648/j.avs.20180602.12

Received: April 20, 2018; Accepted: May 17, 2018; Published: June 15, 2018

\begin{abstract}
The study was carried out to evaluate the effect of alloxan-induced diabetes on some oxidative stress markers in rabbits. Ten rabbits weighing between $1.0-1.5 \mathrm{~kg}$ were used and divided into two groups of five rabbits each. Diabetes was induced in one of the groups, by intraperitonial administration of alloxan at a dosage of $150 \mathrm{mg} / \mathrm{kg}$ body weight and the control rabbits were administered normal saline $(0.9 \% \mathrm{NaCl})$. The animals were monitored for 14days after confirmed diabetes in the test group. The fasting plasma glucose, plasma insulin, plasma lipids, the antioxidant enzymes: Superoxide dismutase (SOD), catalase, and lipid peroxidation were assayed for, in the plasma and the brain of the diabetic and non-diabetic rabbits. The results showed a significant decrease in mean body weight of the alloxan-induced diabetic and control rabbits pre and 14days post alloxan-induction. There was a significant $(\mathrm{p}<0.01)$ increase in fasting plasma glucose, a significant $(\mathrm{p}<0.01)$ decrease in the activity of SOD and a significant $(\mathrm{p}<0.01)$ increase in the activity of catalase in the plasma and brain; there was also a significant $(\mathrm{p}<0.01)$ increase in the level of lipid peroxidation, plasma cholesterol and triglycerides in the diabetic rabbits. Culminating a depletion of SOD activity, the altered activity of plasma (or brain) catalase and increased lipid peroxidation is due to the oxidative stress induced by the diabetic condition, hence the present study indicate that alloxan - induced diabetic potentiated oxidative stress in a short term duration. This shows the importance of antioxidant mimetics to be administered at early stage of diabetics in other to increase the antioxidant capacity thus preventing oxidative stress which may lead to complication in diabetes.
\end{abstract}

Keywords: Oxidative Stress, Alloxan, Superoxide Dismutase, Catalase, Lipid Peroxidation, Antioxidant

\section{Introduction}

Diabetes Mellitus (DM) has been classified as a metabolic disorder primarily characterized by elevated blood glucose level (hyperglycemia) and this may be due to lack of insulin or significantly reduced effectiveness of insulin. Symptoms associated with hyperglycemia include fatigue, weight loss, polyphagia and polyuria. [1]. The world health organization reported that the number of people with diabetes will increase by $150 \%$ in the next 25 years, with an increasing proportion of affected people in the younger age groups [2, 3]. Hyperglycemia increases the risk of developing acute as well as the long-term complications of diabetes. The most common long-term complications of diabetes include cardiovascular disease (CVD), nephropathy, retinopathy and neuropathy. Diabetes is the leading cause of adult blindness, non-traumatic lower limb amputation and end-stage renal disease. $[4,5]$. In healthy individuals, cells utilize oxygen in the making of energy but the process produces free radicals which are toxic by-products that damage the DNA and proteins. The body produces natural antioxidants to sop up those free radicals and reduce the oxidative damage to tissues. The oxidative damage is reduced or prevented by a system of defences which include antioxidant enzymes (SOD, catalase, glutathione peroxidase) and small molecules with scavenging ability such as antioxidant vitamins (A, C and E) [6].

An imbalance between formation and removal of free radicals can lead to a pathological condition called oxidative 
stress. It is of noteworthy that if the generation of free radicals exceeds the protective effects of antioxidants, this can cause oxidative damage which accumulates during the life cycle, and this has been implicated in aging and agedependent diseases such as cardiovascular disease, cancer, neurodegenerative disorders, and other chronic conditions. [6]

In diabetes, there is an altered balance between reactive oxygen species production and total antioxidant status in prolonged diabetes and this has been reported [7]. However much is still yet to be done on the actual status of the individual antioxidant enzymes in diabetes with regards to the early stages of diabetes. Thus the study was designed to ascertain the effect of oxidative stress via the actual status of the antioxidant enzymes in plasma and brain of alloxaninduced diabetes in short term duration.

\section{Materials and Methods}

\subsection{Animal Preparation and Protocol}

Ten Rabbits (10) weighing between $1.0-1.5 \mathrm{~kg}$ were obtained from the laboratory animal Centre, College of Medicine, University of Lagos, Idiaraba. They were housed in stainless steel cages in a well-ventilated room, fed with standard commercial rabbit pellets and water ad libitum. The Rabbits were divided into two groups of five each (Diabetic and Non diabetic). They were fasted for 18 hours and the plasma glucose level for the two groups was determined (baseline glucose level).

\subsection{Induction of Diabetes}

The rabbits were then fasted for 24 hours before injection of a freshly prepared solution of alloxan monohydrate (Span Chemical CO, Mumbai), intraperitonially at a dosage of $150 \mathrm{mg} / \mathrm{kg}$ body weight. The single dose of alloxan produced type 1 diabetes having fasting blood glucose of $\geq 180 \pm 1.58$ $\mathrm{mg} / \mathrm{dl}$. Diabetes was also confirmed 48 hours after administration by symptoms of polyuria and glucosuria using uristic test strip (Bayer Health Care, USA) in the diabetic group. The diabetes was maintained throughout the duration of the experiment. The Non-Diabetic rabbits were administered $2 \mathrm{ml}$ of normal saline $(0.9 \% \mathrm{NaCl})$. The blood glucose level was monitored and recorded on days 1, 5, 10 and 14 from the date of confirmed diabetes (48hours after induction with glucose level of $180 \mathrm{mg} / \mathrm{dl}$, using a Finetest glucometer). At the end of the Experiment, On the $14^{\text {th }}$ day, the rabbits were all sacrificed, blood samples were collected using EDTA and plain bottles and centrifuged for assay of plasma insulin, Superoxide dismutase, catalase, lipid peroxidation, cholesterol and triglyceride estimation. The laboratory animals were handled in accordance with laboratory animal practice regulation and the principle of laboratory animal care as documented by [8].

\subsection{Preparation of Brain Tissue Extract}

The brain tissue homogenate was prepared by the method of [9]. $1 \mathrm{~g}$ of Brain tissue was homogenized with $10 \mathrm{ml}$ of ice cold $0.05 \mathrm{ml}$ phosphate buffer $\mathrm{pH} 7.0$ using a mortar and pestle; centrifuge at $7,000 \mathrm{~g}$ for 20 minutes and the supernatant removed for the assay.

\subsection{Biochemical Assay}

\subsubsection{Estimation of Fasting Plasma Glucose}

Plasma glucose concentration was assayed for by the Glucose oxidase method as described by [10] in the diabetic and Non - diabetic rabbits.

\subsubsection{Estimation of Plasma Insulin}

The method of [11]; an automated Radioimmunoassay technique was adopted to estimate plasma insulin levels.

\subsubsection{Estimation of Total Superoxide Dismutase (SOD) Activity}

The Plasma and brain Total Superoxide Dismutase (SOD) was assayed according to the scheme proposed by [12] which is based on epinephrine autoxidation.

\subsubsection{Estimation of Catalase Activity}

The plasma/brain Catalase was activity was assayed for by the method of [13], which is based on the Hydrogen peroxide-oxidoreductase activity.

\subsubsection{Estimation of Plasma Total Cholesterol}

Plasma cholesterol was assayed for by the method of [14], (colorimetric Kit)

\subsubsection{Estimation of Plasma Triglycerides}

The Plasma Triglycerides was assayed for by the method of [15]. (Colorimetric Kit)

\subsubsection{Estimation of Plasma/Brain Lipid Peroxidation}

Plasma/Brain lipid peroxidation based on the thiobarbituric acid assay according to method of [16].

\subsubsection{Measurement of Body Weight}

The body weight of the animals was determined by using a weighing balance. The initial body weight of each animal was recorded before induction of diabetes. The rabbits were subsequently weighed on days 1, 5, 10 and 14 after confirmed diabetes. The mean body weight was recorded the mean body weight pre and post alloxan was statistically analyzed.

\subsubsection{Statistical Analysis}

Results are presented as mean \pm standard deviation. Data was analyzed statistically using SPSS to test any significant differences between the two groups. A one way analysis of variance (ANOVA) post hoc test was used for comparison of means. Mean values of $p<0.01$ were regarded as statistically significantly.

\section{Results}

\subsection{Fasting Blood Glucose Level in the Diabetic and Non-Diabetic Groups}

Figure 1 show that the rabbits injected with alloxan 
monohydrate had a two fold increase in the level of fasting plasma glucose and the values consistently increased after administration of alloxan, the plasma glucose levels were significantly $(\mathrm{p}<0.01)$ higher than the non-diabetic group. (Figure 1).

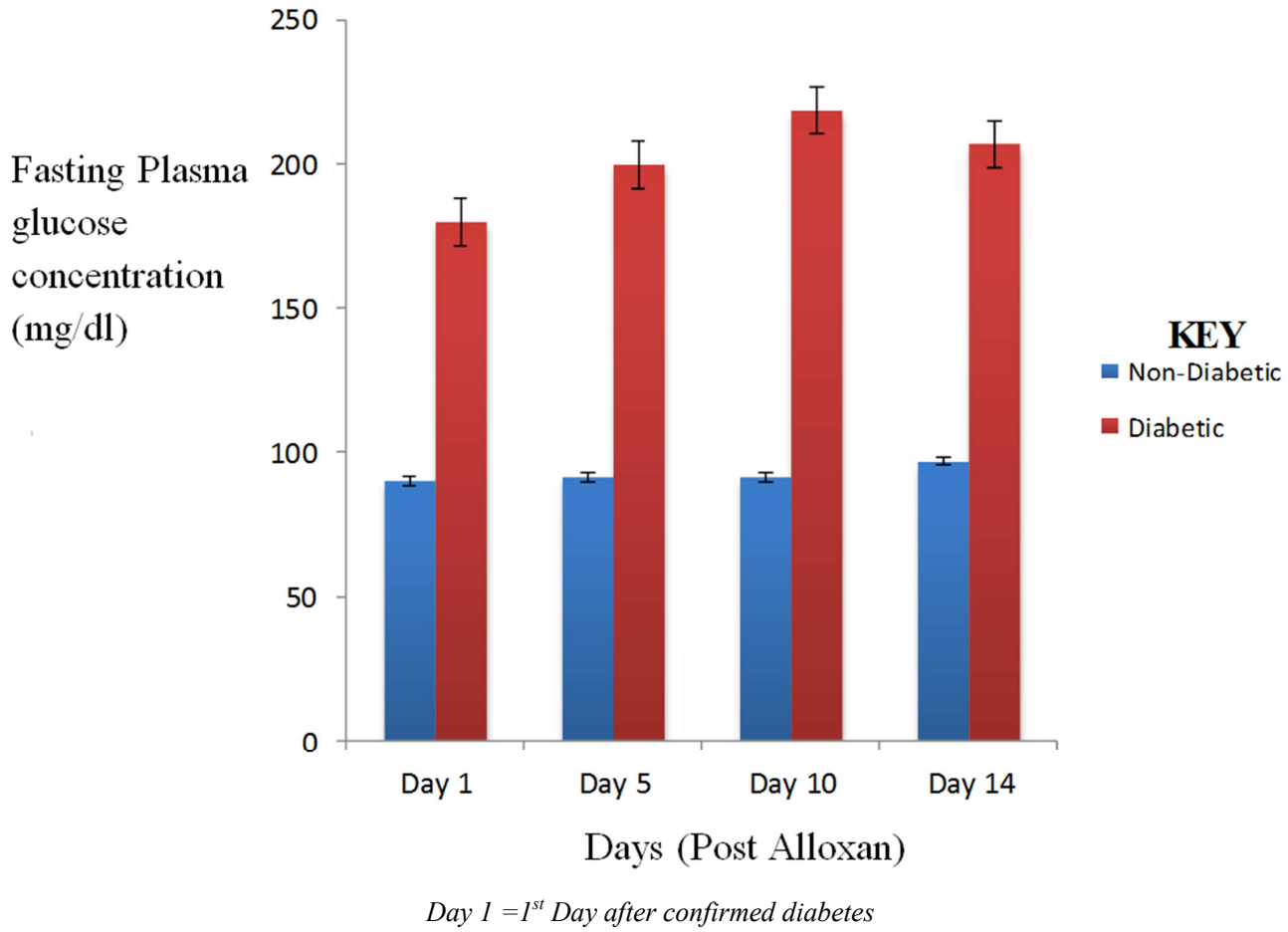

Figure 1. Plasma Glucose Concentration (mg/dl).

\subsection{Plasma Insulin Level in the Diabetic and Non-Diabetic Groups}

There was a significant reduction in the plasma insulin levels of the diabetic group as compared with the non-diabetic group $(\mathrm{p}<0.01)$. Figure 2

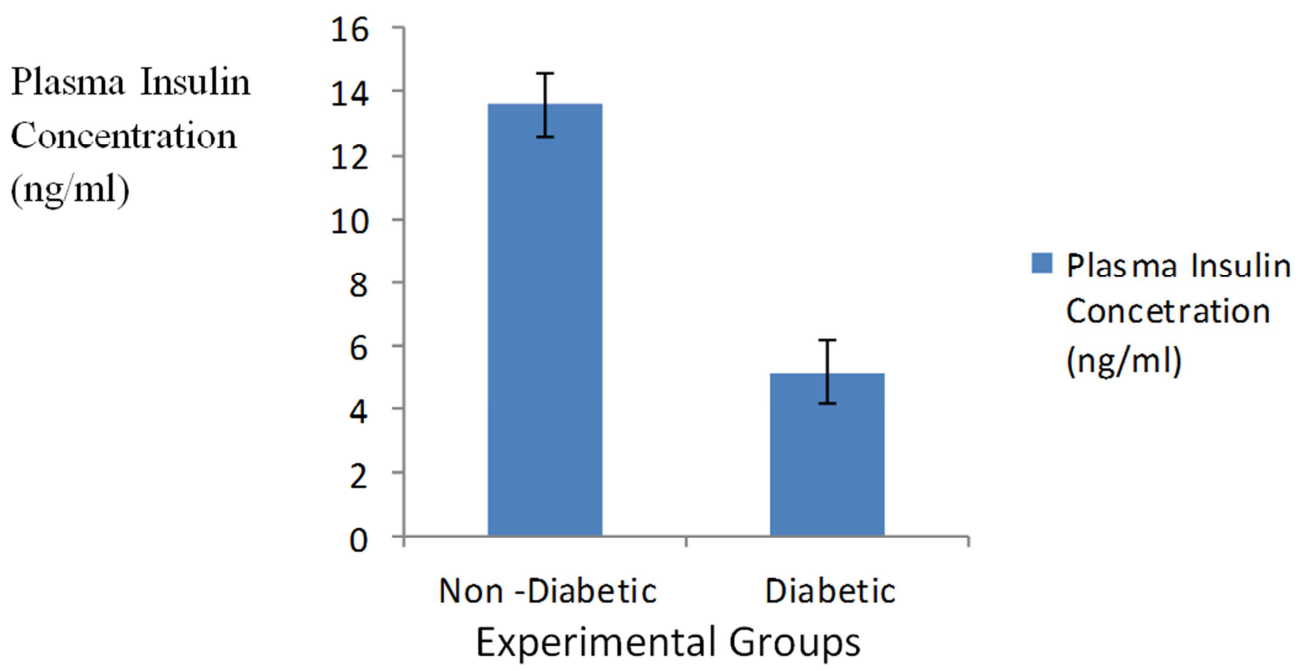

Figure 2. Plasma Insulin Concentration.

\subsection{SOD and Catalase Activities in the Plasma and Brain of Diabetic and Non-Diabetic Groups}

Figures 3 and 4 show a significant $(p<0.01)$ decrease in the activity of SOD and a significant $(p<0.01)$ increase in the activity of catalase in both the brain and plasma of the diabetic group when compared to the non-diabetic group. 


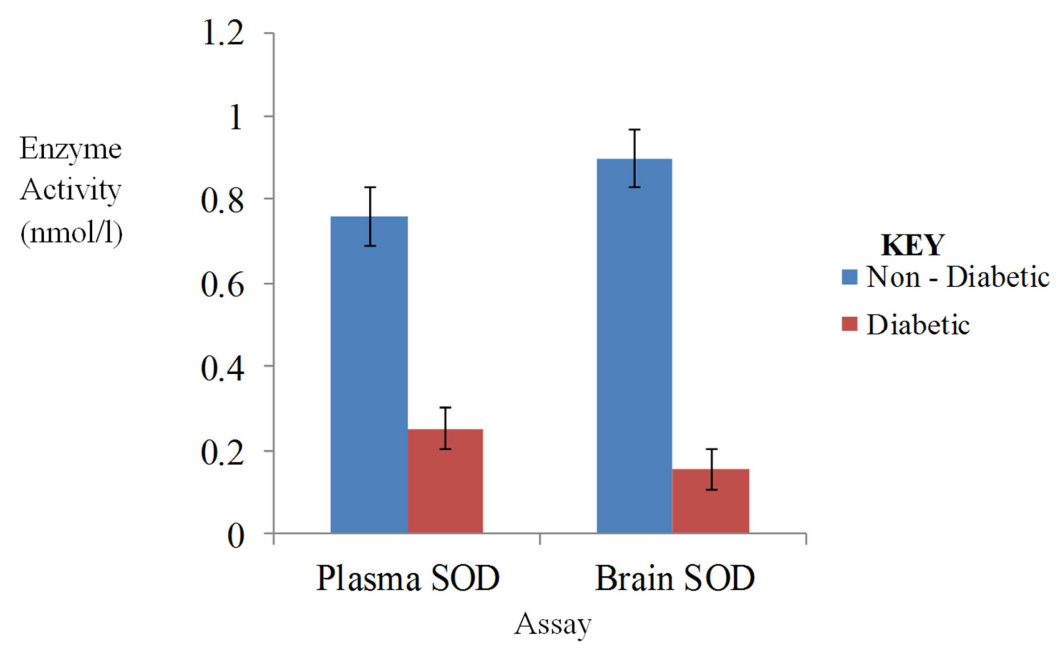

Figure 3. Superoxide Dismutase (SOD).

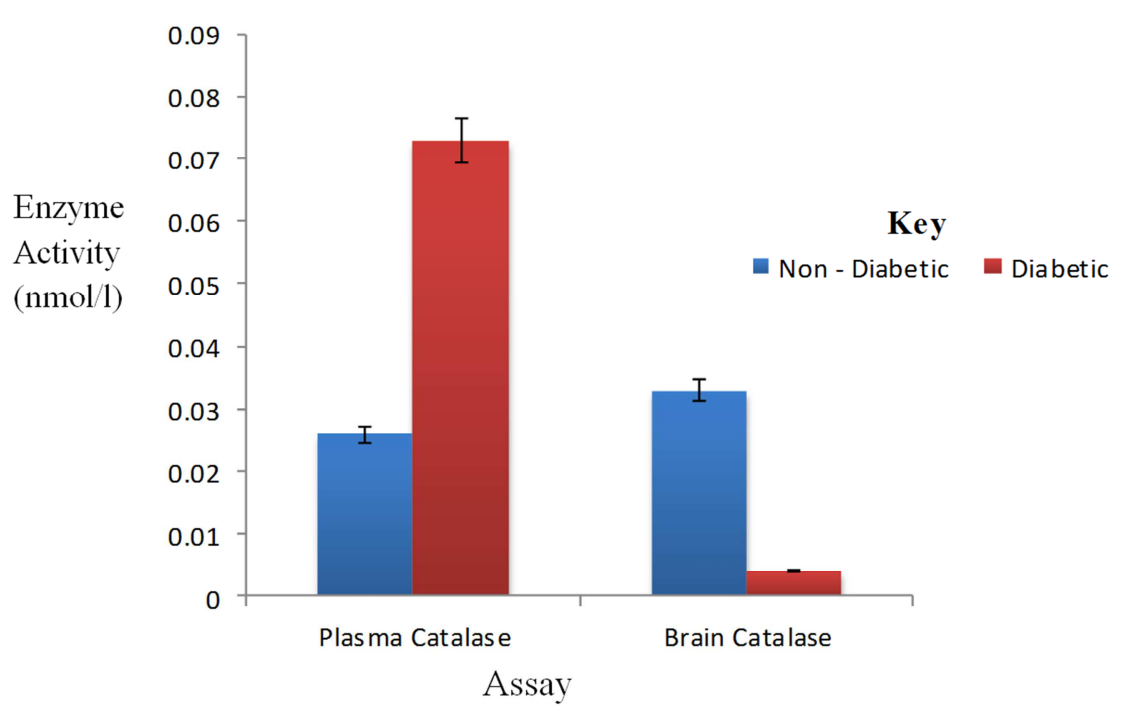

Figure 4. Catalase Activity.

\subsection{Mean Body Weight of the Diabetic and Non-Diabetic Rabbits}

Figure 5 shows the change in the mean body weight of the alloxan-induced diabetic and non-diabetic rabbits; there was significant $(\mathrm{p}<0.01)$ increase in the non-diabetic rabbits; while in the alloxan-induced diabetic rabbits there was a significant $(\mathrm{p}<0.01)$ reduction in mean body weight 14 days post alloxan.

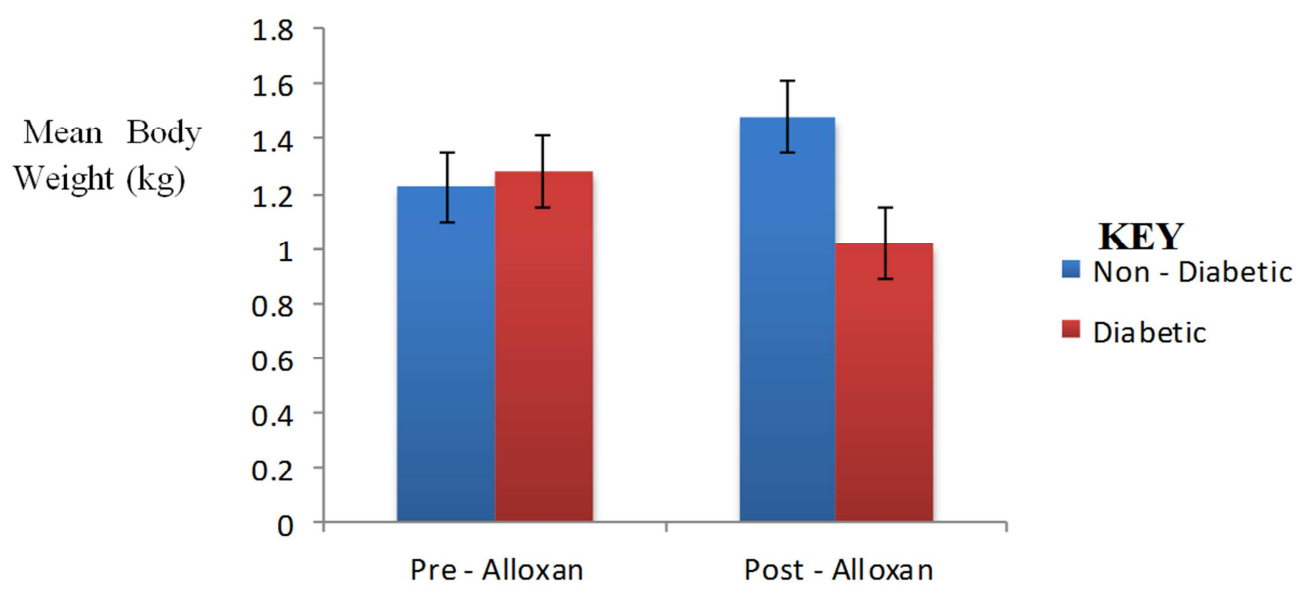

Figure 5. Mean Body weight. 


\subsection{Lipid Peroxidation in Plasma and Brain of the Diabetic and Non-Diabetic Groups}

Figure 6 shows that there was also a significant increase $(\mathrm{p}<0.01)$ in lipid peroxidation in the plasma and brain of the diabetic group when compared with the non-diabetic group.

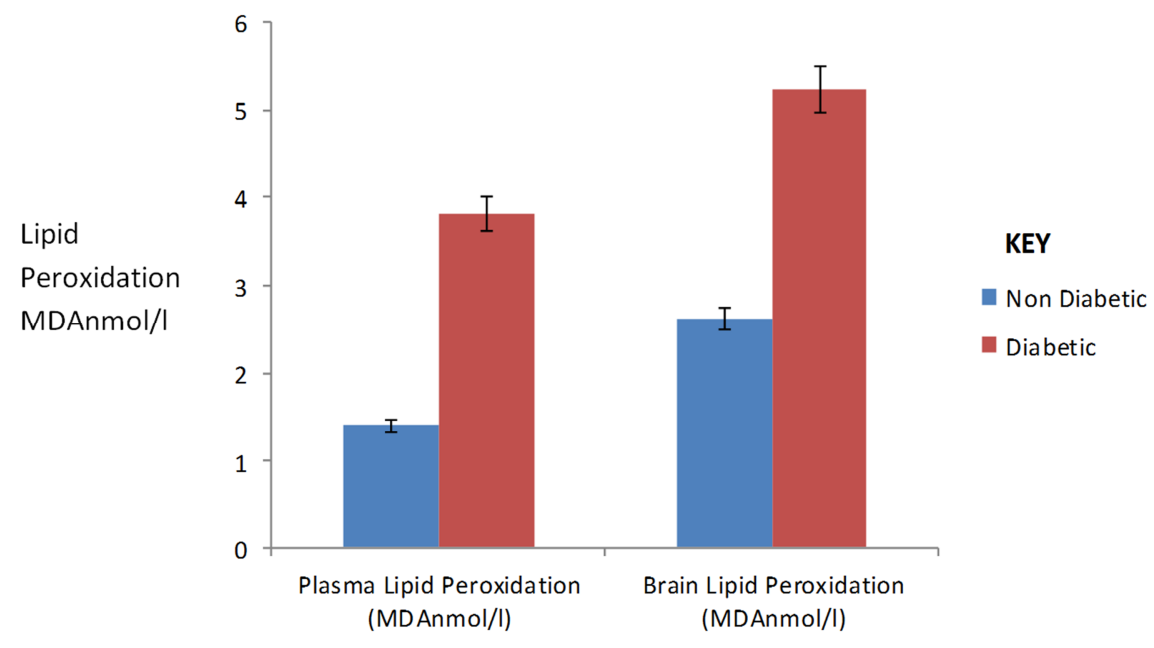

Figure 6. Lipid Peroxidation.

\subsection{Plasma Cholesterol and Triglyceride Levels in the Diabetic and Non-Diabetic Groups}

Figure 7 shows that there was a significant $(\mathrm{p} 0<0.01)$ increase in the cholesterol and triglyceride levels in the diabetic rabbits compared with the non-diabetic rabbit.

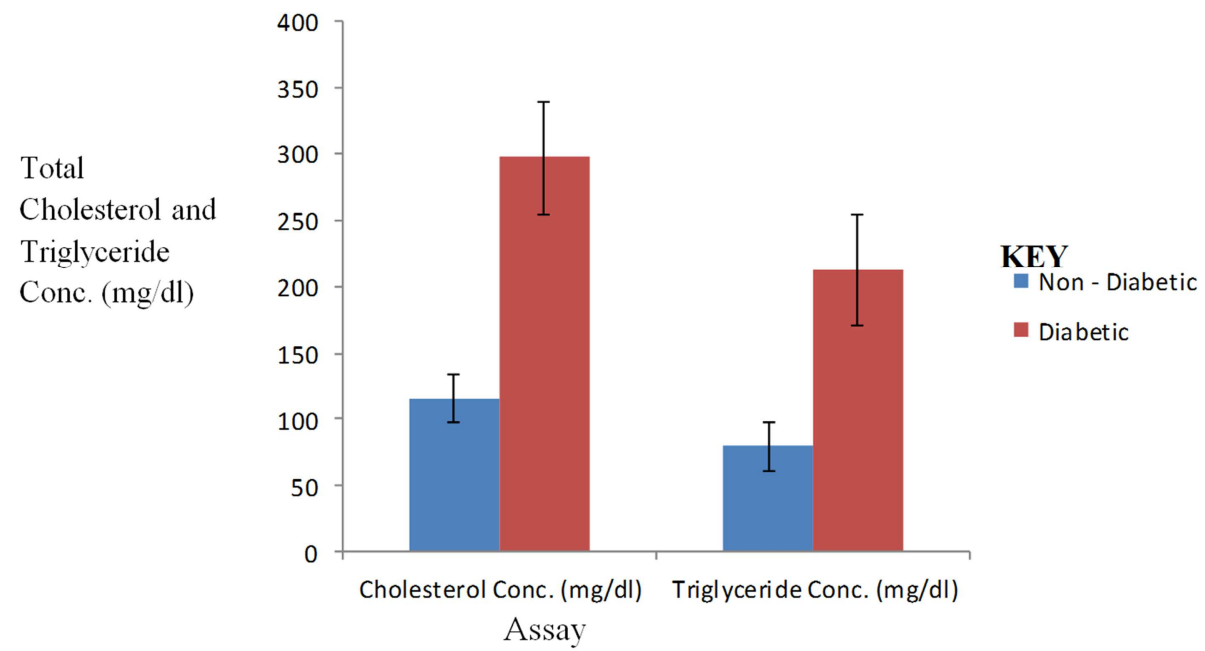

Figure 7. Plasma Total Cholesterol and Triglyceride.

\section{Discussion}

This study was designed to investigate the effect of oxidative stress via the actual status of the antioxidant enzymes in the plasma and brain of alloxan-induced diabetes in short term duration. The level of lipid peroxidation, cholesterol and triglyceride and the activities of two antioxidant enzymes; SOD and catalase were evaluated inother to examine the effect of oxidative stress in the early stage of diabetes.

Alloxan, a beta cytotoxin induces chemical diabetes in a wide variety of animal species through damage of the insulin secreting cells [17]. Diabetes Mellitus is a complex syndrome affecting $3-5 \%$ of people; and long term complications are the main cause of morbidity and mortality. [2] While there are some evidences about the role of oxidative stress in the pathogenesis of diabetic complications but some relationship between hyperglycemia and generation of oxidative stress is still not very clear $[5,18]$.

Oxidative stress results from an imbalance between the generation of reactive oxygen species (ROS) and protective mechanisms. Free radicals, the main cause of oxidative stress, may react with a variety of biomolecules including lipids, carbohydrates proteins and DNA of connective tissues $[19,20]$. Free radicals especially reactive oxygen species (ROS) had been implicated in a lot of degenerative diseases 
such as Parkinsons diseases and diabetes. Overproduction of ROS can directly attack the polyunsaturated fatty acids of cell membranes and induce lipid peroxidation [21,]. Antioxidants are strong reducing agents and this is principally based on the redox relationships between different parts of their chemical structure. Antioxidants carry out their protective properties on cells either by preventing the production of free radicals or neutralizing /scavenging free radicals produced in the body. [22]

In the present study, the induction of diabetes in the diabetic group rabbits was confirmed by a significant rise in the fasting plasma glucose level, since fasting plasma glucose concentration in excess of $180 \mathrm{mg} / \mathrm{dl}$ confirmed the diabetic state. There was a significant reduction in the plasma insulin levels of the diabetic group as compared with the nondiabetic group $(\mathrm{p}<0.01)$. This is expected as a result of the effect alloxan that destroys the $\beta$ cells that secret insulin. [23]

The activity of the antioxidant enzyme SOD in the alloxan - induced diabetic rabbits was significantly $(p<0.01)$ decreased when compared with the non-diabetic rabbits. This finding agrees with another study as carried out by [24, 25], however not compatible with others $[26,27]$. In diabetes the auto-oxidation of glucose results in the formation of hydrogen peroxides and increase in lipid peroxidation which also produces free radicals, thus further depleting the antioxidant enzyme [28]; this may be the reason for the decreased activity of SOD in the diabetic rabbits in the present study.

The result also showed that the enzyme catalase was significantly higher in the brain and plasma of the diabetic group than the non-diabetic group $(\mathrm{p}<0.01)$. Studies carried out by [27], showed a significant increase in catalase and SOD activities on the $6^{\text {th }}$ day of alloxaninduced diabetes; however, as the days progressed, there was a decrease in the level of SOD in both the brain and plasma. Previous study also reported by [29], showed a significant increase in catalase activity in the plasma and brain estimated at 3 weeks of alloxan induced diabetes. This finding agrees with the result of the present study. The increase in catalase activity could be due to the increase in hydrogen peroxides and other peroxides; the body thus increases the activity of catalase in other to cope with the free radicals being produced. However when the level of free radicals due to oxidative stress, exceeds the production of antioxidant enzymes, its activity may progressively decrease as in prolonged diabetes. [29]

There was also a significant increase $(p<0.01)$ in lipid peroxidation in the plasma and brain of the diabetic group when compared with the non-diabetic group. An increase in lipid peroxidation was reported by [30]. Thus in the present study the increase could be due to the increased production of free radicals in the diabetic state which then resulted to an increased destruction of lipid membranes [20]

In the present study, there was a significant $(p<0.01)$ increase in the levels of cholesterol and triglycerides in the diabetic rabbits. This increase may be due to accelerated lipolysis in an insulin deficient condition [22, 31]; this accelerated lipolysis results in elevated plasma fatty acids and triglycerides in the plasma. From literatures, it is also known that there is accelerated conversion of acetyl CoA to cholesterol resulting in an increase in plasma cholesterol in the diabetic. [32]. An increase in the cholesterol levels as observed in the present study, might be due to an increase in the transport of chylomicron cholesterol to the liver. Elevated blood lipid levels have been shown to be associated with increased incidence of cardiovascular diseases and this is a significant complication of diabetes [32].

The loss in weight in the diabetic animals as evidenced in figure 5 would be expected. This was also observed by [Nna 33, 34] This could be attributed to the alloxan which is used to induce type 1 diabetes in the diabetic animals. The destruction of the pancreas results in the utilization of non-carbohydrate moieties such as protein for the synthesis of glucose for energy. This accounts for the depletion of energy stores and weight loss in type 1 diabetes mellitus [22].

Japanese scientists have demonstrated that oxidative stress damages the insulin producing cells of the pancreas in rats, which can worsen diabetes. Their studies suggest that antioxidant supplements such as vitamin $\mathrm{E}$ in animals may reduce that damage [32].

Recent studies demonstrate that a single hyperglycemiainduced process of overproduction of superoxide by the mitochondria electron transport chain seems to be the first and key event in the activation of all other pathways involved in the pathogenesis of diabetes complications [18, 21].

\section{Conclusion}

In conclusion, data of the present study indicate that alloxan-induced diabetes potentiated oxidative stress. Antioxidant properties of brain and plasma SOD, catalase and lipid peroxidation are impaired by diabetes in the early stage in rabbits.

In view of the low activity of SOD and the altered levels of catalase and lipid peroxidation as observed in the diabetic rabbits, it is recommended that supplementary trace elements such as selenium, copper, zinc and manganese, the essential components of the enzyme SOD structures may be useful in preventing of diabetic complications. There are new antioxidant therapies, which consist of low molecular mass compound that act as SOD or catalase mimetics which work as superoxide scavengers being suggested for use. Since there is oxidative stress in a diabetic, due to reactive oxygen specie, these new drugs could be implemented at an early stage to increase the antioxidant capacity thus preventing oxidative stress which may lead to clinical complications in diabetes mellitus. These altered antioxidant defences may increase the susceptibility of diabetics to oxidative injury

\section{Recommendations}

The phytochemistry of antidiabetic and antioxidant plant 
extracts which are natural sources of these elements, could be carried out, to ascertain the level of antioxidants for use in the treatment and management of Diabetes Mellitus. The intake of dietary antioxidants may also help to maintain an adequate antioxidant status in the body.

\section{References}

[1] Bennett, P. H (1994) Definition Diagnosis and classification of Diabetes and impaired glucose tolerance. In joslins diabetes mellitus, ed. by C. kahn and G Weir, $13^{\text {th }}$ ed. Philadelphia, USA, Lea and Ferbiger, 1: p193.

[2] King, H. R., Aubert, E and Herman, W. H. (1998) Global Burden of diabetics (1995-2005) Prevalence, Numerical Estimation and Projection Diabetics care; Vol. 21: 141111431.

[3] World Health Organization (2003) Screening for Diabetes: Report of a World Health Organization and international Diabetes federation Meeting. WHO/NHM/MNC/03.1.http://www.who.int/diabetes/publicatio ns/en/screening_mnc03.pdf.

[4] Bredleharm H. W. (2010) Effect of an Anti-diabetic extract of catharanthos on enzyme activities in Alloxan induced diabetic rats. Journal of Ethno pharmacological Center for Diabetes Control and Prevention $4^{\text {th }}$ Ed.:45-57.

[5] Giacco, F and Brownlee, M. (2010) Oxidative stress and Diabetic Complications. Circulation Research 107 (9): 10581070.

[6] Bhattacharya, S (2015). Reactive Oxygen Species and Cellular Defense Sysetem. In V. Rani and U. C. S. Yadav (eds.), Free Radicals in Human Health and Disease, pp 17-29.

[7] Rahbani, N. (1999). Total Antioxidant capacity and Glutathione peroxidase in Diabetic patients. Medicinal Journal of Islamic Academy of Science 12 (4): 109-114.

[8] Zimmermann, M. (1983). Ethical guidelines for investigations of Experimental pain in Conscious Animals. Pain, 16: 109110.

[9] Aksnes, A and Njaa, L. R. (1981). Catalase, Glutathione peroxidase and Superoxide dismutase in different fish species. Comparative Biochemistry and Physiology, 69B: 893-896.

[10] Cooper, G. R., (1973). Methods for Determining the amount of Glucose in blood. Critical Review of Clinical Laboratory Science, 4: 101-145.

[11] Yallow, R. S and Bearson S. A, (1960) Immunoassay of endogenous plasma in man. Journal of Clinical Investigation. 39: $1157-1175$.

[12] Misra, H. P. and Fridovich, (1972) The role of superoxide ion in the autoxidation of epinephrine and a simple assay for superoxide dismutase. Journal of Biological Chemistry 247: 3174-3175.

[13] Aebi, H., (1967). Catalase: In Methods of enzymatic analysis. edited by Bermeyer H. U. p673-684.

[14] Stein, E. A. (1986): In textbook of clinical chemistry, NW Tiez, Ed. W. B. Sander, Philadelphia, p. p. 879-886.

[15] Stravon Poulous, W. S and Crouch R. D (1974) A New
Colourimeter procedure for the determination of Serum triglyceride. Clinical chemistry 20: 857.

[16] Niehaus, W. G., and Samuelsson, B. (1968). Formation of malonaldehyde from phospholipid arachidonate during microsomal lipid peroxidation. European Journal of Biochemistry. 6:126-130.

[17] Rerrup, C. C. (1990) Drugs producing diabetes through damage of insulin secreting cells. Pharmacological Research; 22: 485-520.

[18] Shinn, S. H. (1998) Oxidative stress and diabetes complications In; Recent advances and pathogenesis and management of diabetes mellitus. $1^{\text {st }}$ ed science co, Singapore. P 3-8.

[19] He L., He T., Farrar, S., Ji, L., Liu, T. and Ma X. (2017). Antioxidants Maintain Cellular Redox Homeostasis by Elimination of Reactive Oxygen Species. Cellular Physiology and Biochemistry 14; 532-55.

[20] West, I. C (2000). Radicals and Oxidative stress in Diabetes. Diabetic Medicine17: 171-180.

[21] Uttara, B Singh A, V., Zamboni, P and Mahajan R. T (2009) (Oxidative Stress and NeurodegenerativeDiseases: A Review of Upstream and Downstream Antioxidant Therapeutic Options. Current Neuropharmacology 7 (1): 65-74.

[22] Elmegeed, G. A., Ahmed, H. A and Hussein, J. S. (2005). Novel synthesized aminosteroidal heterocycles intervention for inhibiting iron-induced oxidative stress. European Journal of Medicinal Chemistry 40 (12): 1283-1294.

[23] Granner, D. K (1996) Hormones of Pancreas and Gastrointestinal tract Jn: Murrray R. K, ed 24. Connecticut USA Appletion and lange. 24: 586-587.

[24] Yu, B. J and Cho, H. C (1993) The activities of erythrocyte antioxidant enzymes in Diabetes mellitus. Korean Journal of internal Medicine Vol 44 p766-774.

[25] Ngaski, A. A (2018). Correlation of Antioxidants Enzymes Activity with Fasting Blood Glucose in Diabetic Patients in Sokoto, Nigeria. British Journal of Medicine and Medical Research, 25 (12):1-6.

[26] Dominigues, C., Ruiz E., Gussinye, M and Carroscossa, A (1990). Oxidative stress at the onset in early stages of type 1 Diabetes in children. Diabetes Care: Vol 21 p1736-1742.

[27] King G. L., Kunisaki. M., Nishio. Y. Inoguch. T., Shiba T. (1996) Biochemical and Molecular mechanisms in the development of diabetes vascular complications. Diabetes. 45 : 105-108.

[28] Matough, F. A Budin, S. B., Hamid Z. A, Alwahaibi, N and Mohamed J. (2012). The Role of Oxidative Stress and Antioxidants in Diabetic Complications. Sultan Qaboos University Medical Journal. 12 (1): 5-18.

[29] Genet, S., Kale, R. K., Bacquer, N. Z (2002) Alterations in Antioxidant Enzymes and Oxidative damage in experimental diabetic rat tissues; Effect of Vanadate and fenugreek. Molecular and Cellular Biochemistry 236: 7-12.

[30] Pari, L and Umamaheswari, J (2000). Anti Hyperglyceamic activity of Musa sapientum flowers: effect on lipid peroxidation in alloxan diabetic rats. Phytotherapy Research 14 (2):136-138. 
[31] Lehninger, A. L., Nelson D. L and M. M, (1993) Principles of Biochemistry $2^{\text {nd }}$ ed. Worth Publishers $p 760$.

[32] Vessby, T. Basu, S., Mohsen, R., Berne C., Vessby, B. (2002). Oxidative stress and antioxidant status in type 1 diabetes mellitus. Journal of Internal Medicine 251: 69-76.

[33] Nna., V. U, Oka, V., O., Aluko E. O. and Helen., O. T, (2013) Comparative Effects of Aqueous Leaf of Viscum Album (mistletoe) and Aleo vera gel in the management of Streptozocin-induced diabetes mellitus. International Journal of Diabetes Research, 3 (4):2306-2316.

[34] Onunogbo, C., Ohaeri., O. C, Eleazu, C. O., Eleazu K C. (2012) Chemical composition of mistletoe extract (Loranthus micranthus) and its effect on the protein, lipid metabolism and the antioxidant status of alloxan induced diabetic rats. E3 Journal of Medical Research; 1 (4):057-062. 